\title{
Electron Exchange Phenomena of Polymers Containing Nitroxyl Radicals
}

\author{
Mikiharu KAMACHI, Masami TAMAKI, Yotaro MORISHIMA, \\ Shun-ichi NOZAKURA, Wasuke MORI,* \\ and Michihiko KISHITA* \\ Department of Macromolecular Science, Faculty of Science, \\ Osaka University, Toyonaka, Osaka 560, Japan. \\ * Department of Chemistry, College of General Education, \\ Osaka University, Toyonaka, Osaka 560, Japan.
}

(Received November 26, 1981)

\begin{abstract}
The influence of electron exchange on the physical properties of polymers containing nitroxyl radical in their side chains has been studied by ESR, magnetic susceptibility measurement and cyclic voltammetry. ESR study shows that the electron exchange interaction between free radicals bound to a polymer chain is more effective than that between the corresponding monomeric radicals. Magnetic susceptibility $\left(X_{\mathrm{M}}\right)$ was measured at temperatures between $4 \mathrm{~K}$ and $273 \mathrm{~K}$. The values of $X_{\mathrm{M}}$ for the polymers obey the Curie-Weise Law $\left(X_{\mathrm{M}}=c /\right.$ $(T-\theta)$ ), where magnetic moments obtained from $X_{\mathrm{M}}$ show the presence of antiferromagnetic interaction between the nitroxyls of a polymer chain, although the interaction is not large enough to bring about long range ordering in the spin orientation of the nitroxyls. In the corresponding monomers, no antiferromagnetic interaction was observed. Cyclic voltammetry in DMF shows that the electrode process in polymer system is a reversible multiple-electron transfer reaction, where the number of the transfer $\left(n_{\mathrm{p}}\right)$ is $60 \%$ of the total free radicals per molecule. A comparison of the shape of the voltammetric response curve in the polymers with that in the corresponding monomers suggests that the interaction between nitroxyl radicals in the polymer is too weak to be reflected in electrochemical behavior.
\end{abstract}

KEY WORDS Electron Exchange / Nitroxyl / ESR / Magnetic Susceptibility / Cyclic Voltammetry / Antiferromagnetic Interaction /

Polymers containing free radicals in their side chains have been of interest in view of the possibility of using them as superconducting material, redox resins, and antioxidants. Several kinds of the polymers have been prepared with these objectives in mind. ${ }^{1-13}$ To our knowledge, no studies on magnetic properties or electrochemical behavior have been carried out. Recently, the possibility of the existence of the magnetically long range ordering of an unpaired electron was pointed out in a study on the magnetic susceptibility $\left(X_{\mathrm{M}}\right)$ of stable organic free radicals in crystals. ${ }^{14-17}$ ESR spectra of polymeric radicals also show that electron ex- change between unpaired electrons is much easier in polymer-bound radicals than in monomeric radicals. ${ }^{1,18,19}$ When free radicals are attached to the side group of a polymer, a long range interaction through the exchange of unpaired electrons is expected to occur in the polymer, thus suggesting the possibility of new magnetic material. ${ }^{20-22}$ In addition, the easier exchange in a polymeric radical might be indicative of physicochemical properties different from those of a monomeric radical. In this paper, ESR, magnetic and electrochemical properties of nitroxyl radicals attached to a polymer are compared with those of a monomeric radical.

Abbreviations: MOTMP, 4-methacryloyloxy-2,2,6,6-tetramethylpiperidine-1-oxyl; TEMPOL, 4-hydroxy-2,2,6,6tetramethylpiperidine-1-oxyl; poly(MOTMP), poly(4-methacryloyloxy-2,2,6,6-tetramethylpiperidine-1-oxyl); and poly(MATMP), poly(4-methacryloylamino-2,2,6,6-tetramethylpiperidine-1-oxyl). 


\section{EXPERIMENTAL}

\section{Materials}

Acetone was dried over calcium chloride for $24 \mathrm{~h}$, filtered, and distilled over calcium chloride. Methanol was refluxed over magnesium turnings containing a trace of iodine and distilled. Ether was dried with calcium chloride, filtered, refluxed over sodium for $3 \mathrm{~h}$ and distilled.

Raney $\mathrm{Ni}$ was prepared according to the procedure in Organic Synthesis. ${ }^{23}$ Butyl lithium obtained commercially was used without further purification.

TEMPOL was synthesized according to the procedure of Kurosaki et al. ${ }^{4}$ Yield $87 \%$, mp 71.5$73^{\circ} \mathrm{C}$ (lit. ${ }^{4} 72-73^{\circ} \mathrm{C}$ ).

MOTMP was synthesized according to the procedure of Kurosaki et al. ${ }^{4}$ Yield $95 \%$, mp $92-94^{\circ} \mathrm{C}$ (lit. ${ }^{4} 82-84^{\circ} \mathrm{C}$ ). Found: $\mathrm{C}, 65.04 ; \mathrm{H}, 9.22 ; \mathrm{N}=$ $5.82 \%$. Calcd for $\mathrm{C}_{13} \mathrm{H}_{22} \mathrm{O}_{3} \mathrm{~N}: \mathrm{C}, 64.97 ; \mathrm{H}, 9.23 ; \mathrm{N}$, $5.83 \%$.

MATMP was prepared according to the procedure of Kurosaki et al. ${ }^{4}$ Yield $80 \%$, mp 149 $151^{\circ} \mathrm{C}$ (lit. ${ }^{4} 147-148^{\circ} \mathrm{C}$ ).

Poly(MOTMP) was obtained by the polymerization of MOTMP with butyl lithium in THF at $0^{\circ} \mathrm{C}$. The polymer was precipitated with ether and reprecipitated with benzene-ether. The degree of polymerization of poly(MOTMP) was determined to be 603 .

Poly(MATMP) was obtained by the oxidation of poly(4-methacryloylamino-2,2,6,6-tetramethylpiperidine) according to the method of Kurosaki et al. ${ }^{4}[\eta]=0.3-0.5$ (Ethanol)

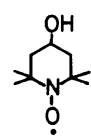

TEMPOL<smiles>CC(C)C(=O)OC1CC2CCC(O2)C1C(=O)O</smiles>

MOTMP

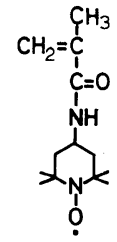

MATMP

\section{Measurements}

ESR was measured with a Japan Electron Optics Laboratory Model JES FE 1X ESR spectrometer with $100 \mathrm{kHz}$ modulator:

Magnetic susceptibility was determined by the Faraday method, using a Cahn electric balance in a temperature range from $4 \mathrm{~K}$ to $273 \mathrm{~K}$.

Cyclic voltammetry was performed in a twocompartment cell separated by fine porosity sintered glass frits. The working electrode, a small platinum plate $\left(0.016 \mathrm{~cm}^{2}\right)$ sealed in glass, was polished before each use with $0.5-\mu$ alumina polishing powder. The counter electrode consisted of a platinum wire. The reference electrode (SCE) was isolated in separate chamber. The test solution (0.1 M tetramethylammonium perchlorate in DMF) was purged of air with argon. Voltammograms were obtained with a Hokuto Denko Potentiostat Model HA 104. A positive feedback technique was applied to compensate for the IR drop.

GPC measurement was carried out with a TOYO SODA high speed liquid chromatograph HLC810A. THF was used as the solvent. Viscosity was measured in an Ubbelohde dilution viscometer at $30^{\circ} \mathrm{C}$ using ethanol as the solvent.

\section{RESULTS AND DISCUSSION}

\section{ESR Study}

The ESR spectra of TEMPOL and poly(MOTMP) are shown in Figure 1 and 2. In the case of TEMPOL, the line shape depends on the concentration of the radical: three sharp lines were observed at $1.7 \mathrm{mM}$, and became broader at

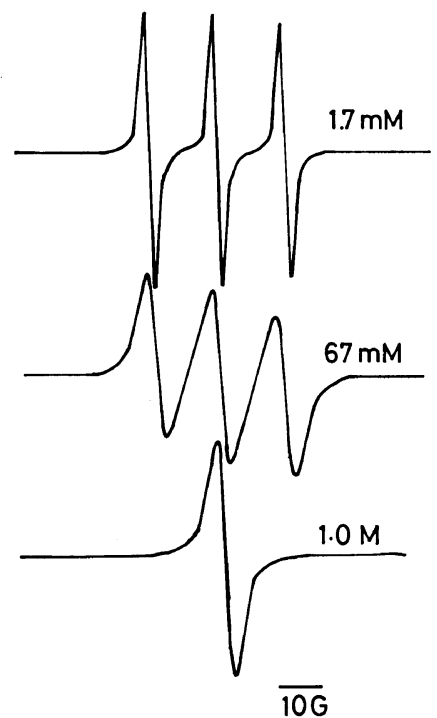

Figure 1. ESR spectra of TEMPOL at various concentrations. (A) $1.7 \mathrm{mM}$; (B) $67 \mathrm{mM}$; (C) $1.0 \mathrm{M}$. 


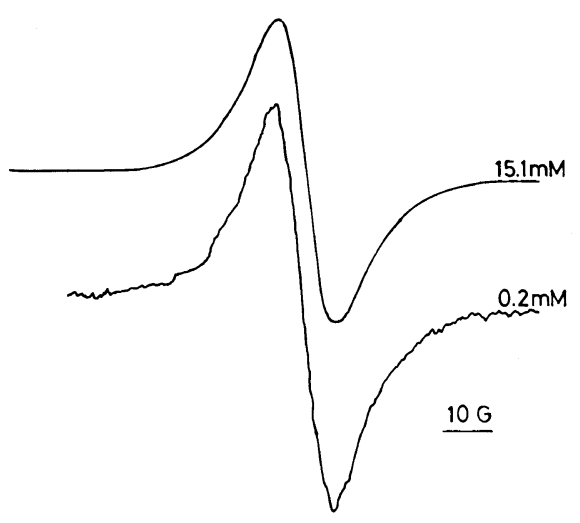

Figure 2. ESR spectra of poly(MOTMP) at various concentrations. (A) $0.2 \mathrm{mM}$; (B) $15.1 \mathrm{mM}$.

Table I. Magnetic susceptibilities of nitroxyl binding to polymers and the isolated nitroxyls

\begin{tabular}{|c|c|c|}
\hline \multirow{2}{*}{ Samples } & Temperature & $X_{\mathrm{M}}$ \\
\hline & $\mathrm{K}$ & $10^{-6} \mathrm{~cm}^{3} \mathrm{~mol}^{-1}$ \\
\hline \multirow[t]{2}{*}{ Poly(MOTMP) } & 10.4 & 28826 \\
\hline & 272.0 & 1302 \\
\hline \multirow[t]{2}{*}{ MOTMP } & 10.2 & 35220 \\
\hline & 274.0 & 1329 \\
\hline \multirow[t]{2}{*}{ Poly(MATMP) } & 10.2 & 28853 \\
\hline & 274.0 & 1314 \\
\hline \multirow[t]{2}{*}{ MATMP } & 10.3 & 35217 \\
\hline & 274.5 & 1314 \\
\hline
\end{tabular}

$67 \mathrm{mM}$, and then coalesced to form a single line at $1.0 \mathrm{M}$. From these spectra, it was evident that initial electron exchange began at an order of $10^{-2} \mathrm{M}$. The ESR spectra of poly(MOTMP) showed a single line even at $0.1 \mathrm{mM}$ of the radical unit and was independent of concentration. Thus, electron exchange between unpaired electrons of poly(MOTMP) was found to be much easier than the intermolecular exchange of TEMPOL, indicating the possible existence of a long range ordering in the orientation of spins in the polymer. The same phenomena were observed in the ESR spectra of poly(MATMP), although the spectra are not shown.

\section{Magnetic Susceptibility}

The electron exchange interaction is considered to reflect magnetic susceptibilities. The molar magnetic susceptibilities $\left(X_{\mathrm{M}}\right)$ of poly(MOTMP),

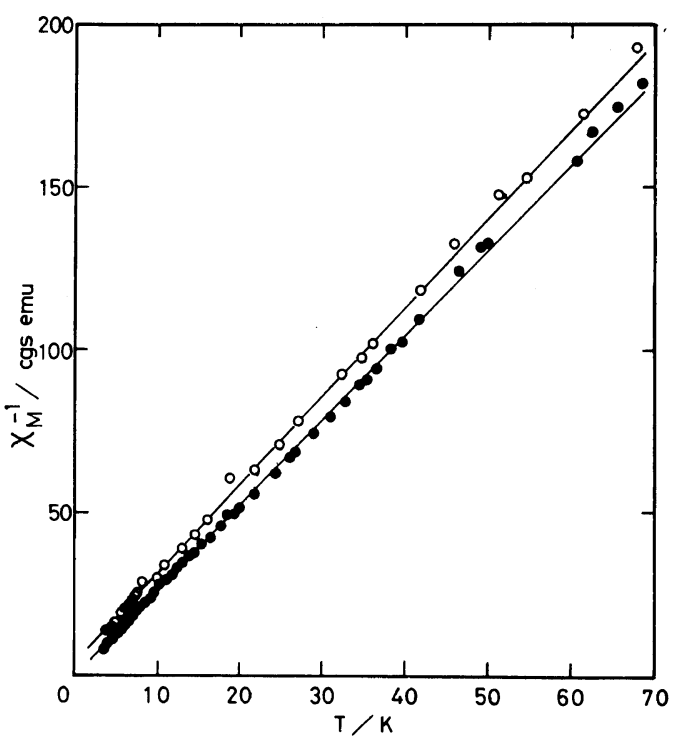

Figure 3. Relation between reciprocal magnetic susceptibility and temperature. (O) poly(MOTMP); ( MOTMP.

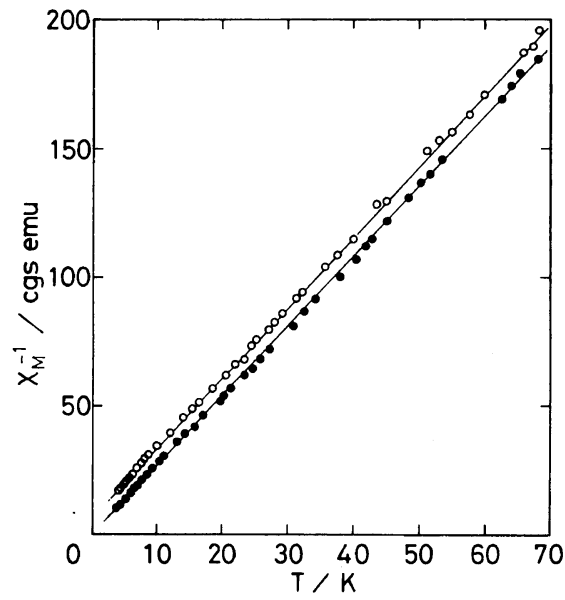

Figure 4. Relation between reciprocal magnetic susceptibility and temperature. (O) poly(MATMP); MATMP.

poly(MATMP), MATMP, and MOTMP were determined at $4 \mathrm{~K}$ through $273 \mathrm{~K}$. The results at $10 \mathrm{~K}$ and $273 \mathrm{~K}$ are shown in Table I. The values of $X_{\mathrm{M}}$ for the polymer at $273 \mathrm{~K}$ are almost the same as those for the corresponding monomer, while the values for the polymer are larger than those for the 
monomer at $4 \mathrm{~K}$. The temperature dependence of $X_{\mathrm{M}}$ of MOTMP and poly(MOTMP) is shown in Figure 3. A good linear relation between $X_{\mathrm{M}}{ }^{-1}$ and temperature was observed in all cases, indicating that there is no transition to the ordered state of an unpaired electron in the temperature range specified. The same was observed in MATMP and poly(MATMP) (Figure 4).

Since the straight lines between $X_{\mathrm{M}}{ }^{-1}$ and temperature pass through the origin of MOTMP and MATMP, the observed $X_{\mathrm{M}}$ obey the Curie law $\left(X_{\mathrm{M}}=c / T\right)$ with $c=0.385$ and 0.380 for MOTMP and MATMP, respectively. In order to obtain

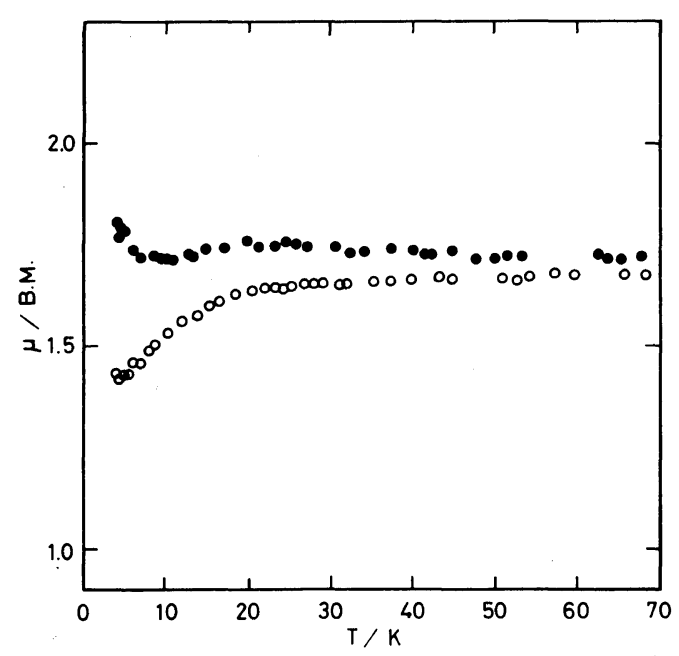

Figure 5. Temperature dependence of magnetic moment. (O) poly(MOTMP); (O) MOTMP.

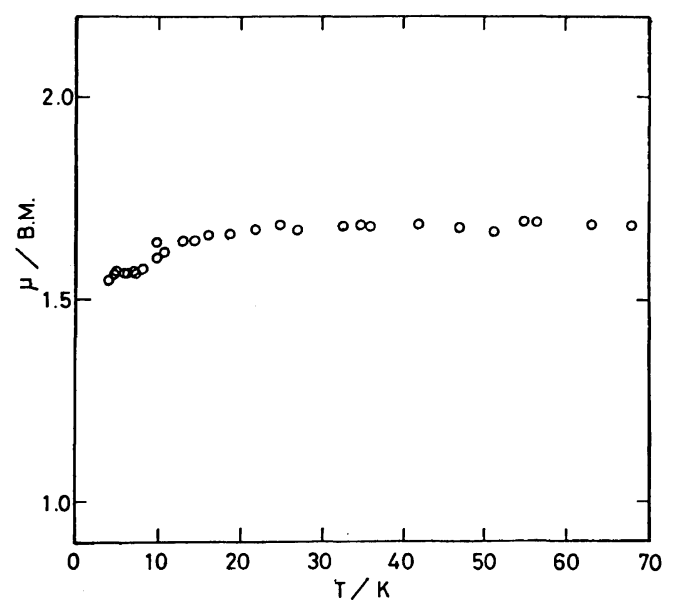

Figure 6. Temperature dependence of the magnetic moment of poly(MATMP). information on interaction between unpaired electrons, the magnetic moment $(\mu)$ for all samples was estimated by $\mu=2.8 X_{\mathrm{M}} \cdot T$. The temperature dependence of $\mu$ of MOTMP is shown in Figure 5, indicating that $\mu$ for MOTMP is $1.75 \mathrm{BM}$ above $6 \mathrm{~K}$ (BM, Bohr Magneton) and close to $1.73 \mathrm{BM}$ for a free electron. The exchange interaction between unpaired electrons is thus concluded to be negligibly small in MOTMP. An increase in $\mu$ below $6 \mathrm{~K}$ cannot be explained at the present time, since the electron exchange interaction between the organic radicals has been found to lead to a decrease in $\mu$ at lower temperature owing to an antiferromagnetic interaction. ${ }^{20}$ The magnetic moment for MATMP was also found to be $1.74 \mathrm{BM}$, indicating that free radicals in MATMP behave as isolated free radicals.

For poly(MOTMP), the straight line between $X_{\mathrm{M}}{ }^{-1}$ and temperature intersects the ordinate in the positive part, indicating that the observed $X_{\mathrm{M}}$ obey the Curie-Weise Law $\left(X_{\mathrm{M}}=c /(T-\theta)\right)$ with $c=$ 0.381 and $\theta=-3.3$, suggesting an antiferromagnetic exchange interaction between unpaired electrons. The $\mu$ of poly(MOTMP) was smaller than that of MOTMP (Figure 5), affirming the occurrence of an antiferromagnetic interaction between the unpaired electrons of the polymer. The temperature dependence of $\mu$ estimated in poly(MOTMP) shows that the magnetic moment gradually decreased by lowering the temperature from $70 \mathrm{~K}$ to $20 \mathrm{~K}$ and remarkably decreased below $20 \mathrm{~K}$. This result shows that an antiferromagnetic interaction between unpaired electrons overwhelms the thermal energy below $20 \mathrm{~K}$. A similar result was also obtained for poly(MATMP) (Figure 6). Thus, the polymer free radicals are more likely to interact than the corresponding monomer radicals. However, since the transition to the ordered form of the unpaired electrons was not observed in the relation between $X_{\mathrm{M}}{ }^{-1}$ and temperature in the polymer system, the interaction between the polymer radicals is considered to be very weak.

\section{Cyclic Voltammetry}

The ESR study showed that the unpaired electrons of poly(MOTMP) or poly(MATMP) exchanged their spin state at a concentration of $10^{-4} \mathrm{M}$ of the radical unit, and that this rapid exchange did not occur at $10^{-2} \mathrm{M}$ of the corresponding monomer radical. Considerable ESR 
study on the electron transfer between neutral molecules and their radical ion has already been reported. $^{1,18,19}$ Thus, the successive electron transfer along the side groups of a polymer to oxidized residues on an electrode surface seems to be effective in the polymer system. In order to obtain information on the effect of electron transfer along polymer side group on electrochemical behavior, the cyclic voltammogram of poly(MOTMP) in a DMF solution was compared with that of TEMPOL. The results are shown in Figure 7. The current-potential response curves for poly(MOTMP) are similar to those for TEMPOL except for the peak current, and show the characteristics of a reversible one-electron transfer resulting in the production of a soluble, stable product, i.e., $E_{\mathrm{a}}$ and $E_{\mathrm{c}}$ are independent of the scanning rate $(V)$, $E_{\mathrm{a}}-E_{\mathrm{c}} \simeq 60 \mathrm{mV}$, and $i_{\mathrm{pa}} / i_{\mathrm{pc}} \simeq 1$, where $i_{\mathrm{pa}}$ and $i_{\mathrm{pc}}$ are the anodic and cathodic peak currents, and $E_{\mathrm{a}}$ and

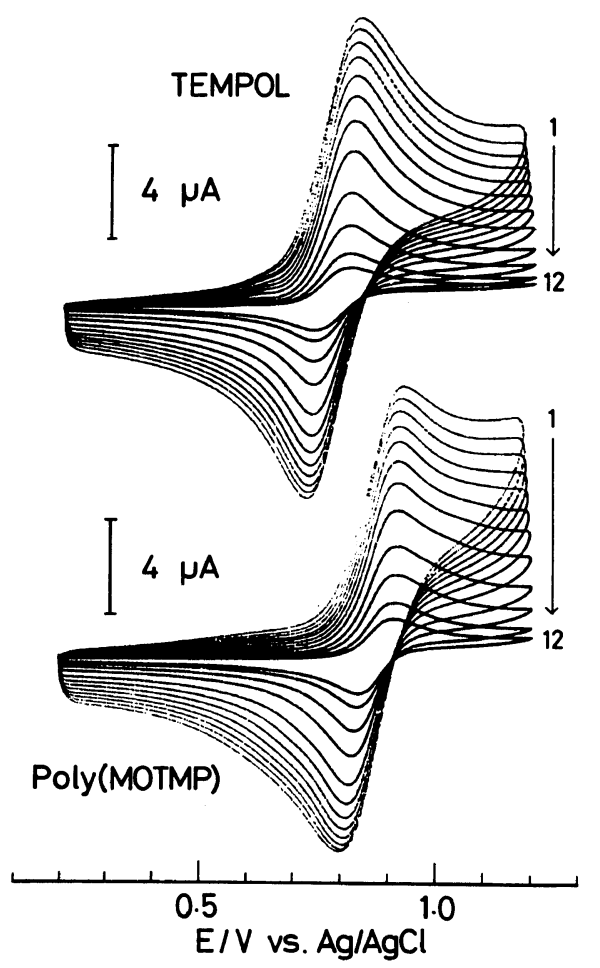

Figure 7. Cyclic voltammograms for TEMPOL $(2.86 \mathrm{mM})$ and MOTMP $(25.4 \mathrm{mM})$ in $0.1 \mathrm{M}$ tetramethylammonium perchlorate solution in DMF at Pt electrode obtained at various scanning rates; $v=1800$, $1600,1400,1200,1000,800,600,400,200,100,40$, and $20 \mathrm{mV} \mathrm{s}^{-1}$ for curves $1-12$, respectively.
$E_{\mathrm{c}}$ are the anodic and cathodic peak potentials, respectively. The standard redox potential $\left(E_{0}\right)$ was estimated as the arithmetical mean value of $E_{\mathrm{a}}$ and $E_{\mathrm{c}}$ in all systems (Table II). The potential was somewhat higher in polymer radicals than in the corresponding monomer radicals and TEMPOL. This small difference seems compatible with the fact that electron interaction between radical units in a polymer is not large enough to energeti-

Table II. Standard redox potentials and peak potentials ${ }^{\mathrm{a}}$

\begin{tabular}{lccc}
\hline & $E_{\mathrm{p}, \mathrm{a}}{ }^{\mathrm{b}}$ & $E_{\mathrm{p}, \mathrm{c}}{ }^{\mathrm{c}}$ & $E_{0}{ }^{\mathrm{d}}$ \\
\cline { 2 - 4 } Samples & \multicolumn{3}{c}{$V v s . \mathrm{Ag} / \mathrm{AgCl}$} \\
\hline & 0.80 & 0.74 & 0.77 \\
TEMPOL & 0.82 & 0.76 & 0.79 \\
MOTMP & 0.76 \\
MATMP & & 0.87 \\
Poly(MOTMP) & 0.90 & 0.84 & 0.76 \\
\hline a 0.1 M tetramethylammonium perchrolate $/ \mathrm{DMF}$ at Pt \\
plate electrode. \\
b Anodic peak potential at a scanning rate of $20 \mathrm{mV} \mathrm{s}^{-1}$. \\
c Cathodic peak potential at the scan rate of $20 \mathrm{mV} \mathrm{s}^{-1}$. \\
d Standard redox potential: $E_{0}=\left(E_{\mathrm{p}, \mathrm{a}}+E_{\mathrm{p}, \mathrm{c}}\right) / 2$.
\end{tabular}
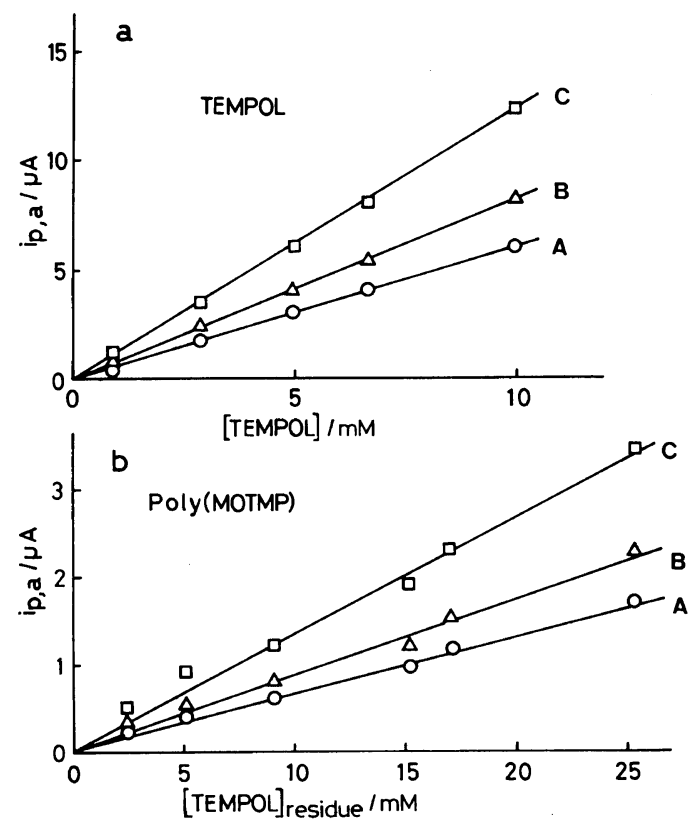

Figure 8. Relation between anodic peak current and concentration of nitroxyl radicals of TEMPOL and poly(MOTMP) at various scanning rates: (A) $20 \mathrm{mV} \mathrm{s}^{-1}$; (B) $40 \mathrm{mV} \mathrm{s}^{-1}$; (C) $100 \mathrm{mV} \mathrm{s}^{-1}$. 
cally bring about any change in the electronic nature of the radicals. In the case of a molecule containing a number of noninteracting redox centers, theoretical analysis has shown that the current-potential response curve for multiple electron transfer is in the same shape as that obtained with the corresponding molecules containing a single center. The similarity of the cyclic voltammogram of poly(MOTMP) with that of MOTMP also shows that the interaction between nitroxyl radicals in poly(MOTMP) is very weak. The $i_{\mathrm{pa}}$ exhibited by MOTMP or TEMPOL is greater than that of poly(MOTMP), suggesting that the electron transfer reaction at the electrode is controlled by diffusion of the redox species.

For further understanding of the behavior of the cyclic voltammogram, the relations between $i_{\mathrm{pa}}$ and sweep rate $(v)$ and between $i_{\mathrm{pa}}$ and the concentration of redox species $(C)$ were investigated for all systems. The linear relation between $i_{\mathrm{pa}}$ and $C$ and that between $i_{\mathrm{pa}}$ and $v^{0.5}$ was observed for all systems
(Figures 8 and 9). Both MOTMP and poly(MOTMP) systems are thus considered to be Nernstian systems and nitroxyl radicals on a polymer chain are considered to behave as independent redox species in a cyclic voltammogram.

The total number of electrons transfered in an oxidation wave for a polymer $\left(n_{\mathrm{p}}\right)$ was estimated from the peak currents of the polymer and the monomer by the following relation: ${ }^{27}$

$$
n_{\mathrm{p}}=\frac{i_{\mathrm{pa}, \mathrm{p}} /[\mathrm{C}]_{\mathrm{p}}}{i_{\mathrm{pa}, \mathrm{m}} /[\mathrm{C}]_{\mathrm{m}}} P_{n}{ }^{1.275}
$$

where $i_{\mathrm{pa}, \mathrm{p}}$ and $i_{\mathrm{pa}, \mathrm{m}}$ are the anodic peak currents of the polymer and the monomer, $[\mathrm{C}]_{\mathrm{p}}$ and $[\mathrm{C}]_{\mathrm{m}}$, the residual concentrations of nitroxyl radicals of the polymer and monomer, and $P_{n}$, the degree of polymerization. The values of $n_{\mathrm{p}}$ estimated at various scanning rates for poly(MOTMP) are shown in Table III, and constitute about $60 \%$ of the total radical units of the polymer. The $n_{\mathrm{p}}$ values for poly(vinylnaphthalene) and poly(vinylferrocene)

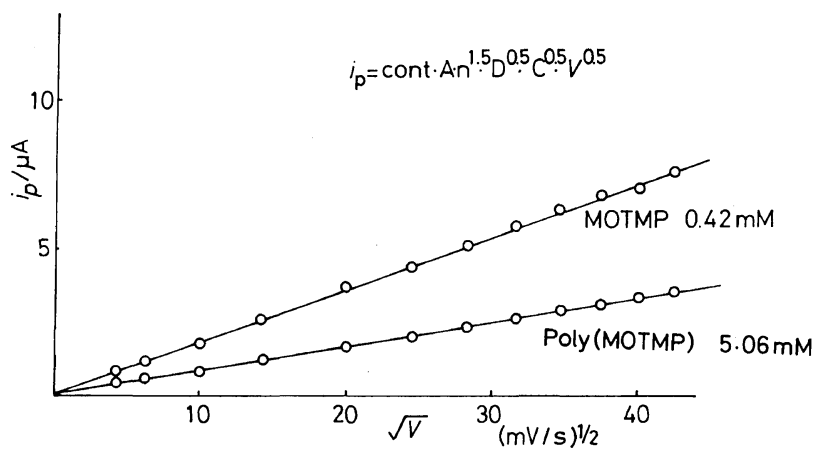

Figure 9. Relation between anodic peak current and the square root of the scanning rate for MOTMP and poly(MOTMP).

Table III. Number of electrons $\left(n_{\mathrm{p}}\right)$ involved in the oxidation of poly(MOTMP)

\begin{tabular}{cccccc}
\hline \multirow{2}{*}{ Polymer } & \multicolumn{1}{c}{$V^{\mathrm{a}}$} & $i_{\mathrm{p}, \mathrm{p}} /[\mathrm{C}]_{\mathrm{p}}^{\mathrm{b}}$ & $i_{\mathrm{p}, \mathrm{m}} /[\mathrm{C}]_{\mathrm{m}}{ }^{\mathrm{c}}$ & $n_{\mathrm{p}}{ }^{\mathrm{d}}$ & $n_{\mathrm{p}} / P_{n}$ \\
\cline { 2 - 6 } & $\mathrm{mV} \mathrm{s}^{-1}$ & & & & \\
\hline & 20 & 0.065 & 0.60 & 380 & 0.63 \\
Poly(MOTMP) & 40 & 0.084 & 0.81 & 364 & 0.60 \\
$\left(P_{n}=603\right)^{\mathrm{e}}$ & 100 & 0.13 & 1.22 & 374 & 0.62 \\
\hline
\end{tabular}

a Scanning rate.

b Calculation from the slopes of straight lines in Figure $8 \mathrm{~b}$.

c Calculation from the slope of straight lines in Figure 8a.

d Calculated from Scheme 1.

e Degree of polymerization determined by GPC. 
have been reported to correspond to the degree of polymerization. ${ }^{28,29}$ According to eq $1, n_{\mathrm{p}}$ seems somewhat insensitive to $P_{\mathrm{n}}$, e.g., when $P_{\mathrm{n}}$ is 300 or 1200 (a half or double of $P_{\mathrm{n}}=603$ ), $n_{\mathrm{p}}$ is 156 or 912 , respectively. This corresponds to an efficiency of $56 \%$ and $76 \%$. Thus, the observed inefficiency can hardly be atrributed to an erroneous estimation of $P_{n}$. Accordingly, the electron transfer at the electrode is concluded to be less effective in poly(MOTMP) than in either poly(vinylnaphthalene) or poly(vinylferrocene). It might be permissible to ascribe the smaller $n_{\mathrm{p}}$ value in poly(MOTMP) to the much smaller interaction between MOTMP groups in the polymer as compared to that between either the naphthyl groups or ferrocenyl groups, whose $\pi$-electrons are delocalized. More data on the cyclic voltammogram of polymers involving electron transfer and electron exchange is necessary for a more complete understanding of this phenomenon.

Acknowledgement. This research was supported in part by a Grant-in-Aid for Scientific Research from the Ministry of Education, Science and Culture of Japan.

\section{REFERENCES}

1. B. Ranby and J. F. Rabek, "ESR Spectroscopy in Polymer Research," Springer Verlag, Berlin, 1977.

2. D. Braun, J. Polym. Sci., C, No. 24, 7 (1968).

3. Y. Miura, K. Nakai, and M. Kinoshita, Makromol. Chem., 172, 233 (1973).

4. T. Kurosaki, K. W. Lee, and M. Okawara, J. Polym. Sci., Polym. Chem. Ed., 10, 3295 (1972).

5. T. Kurosaki, K. W. Lee, and M. Okawara, J. Polym. Sci., Polym. Chem. Ed., 12, 1407 (1974).

6. D. Braun and S. Hauge, Makromol. Chem., 150, 57 (1971).

7. Y. Kurisu, H. Yoshida, and M. Okawara,
Tetrahedron Lett., 44 (1967).

8. Y. Miura, M. Kinoshita, and M. Imoto, Makromol. Chem., 146, 69 (1971).

9. M. Kinoshita and R. C. Schulz, Makromol. Chem., 111, 137 (1968).

10. M. Kato and Y. Nakano, J. Polym. Sci., B, 10, 157 (1972).

11. M. Kato, Y. Takemoto, and Y. Nakano, J. Polym. Sci., Polym. Chem. Ed., 13, 1901 (1975).

12. Y. Kurisu, H. Yoshida, and M. Okawara, Kogyo Kagaku Zasshi, 72, 1402 (1969).

13. F. A. Neugebauer and H. Trishmann, J. Polym. Sci., $B, 6,255$ (1968).

14. J. Yamauchi, J. Chem. Phys., 67, 2850 (1977).

15. J. Yamauchi, Bull. Chem. Soc., Jpn., 44, 2301 (1971).

16. K. Ushino, J. Yamauchi, H. Ohya-Nishiguchi, and Y. Deguchi, Bull. Chem. Soc., Jpn., 47, 285 (1974).

17. W. Duffy, Jr., J. F. Dubach, P. A. Pianetta, J. F. Deck, D. L. Standburg, and A. R. Miedema, J. Chem. Phys., 56, 2555 (1972).

18. M. Szwarc and K. Shimada, J. Polym. Sci., Polym. Symp., No. 46, 193 (1974).

19. K. Shimada, G. Moshak, H. D. Conner, P. Caluwee, and M. Szwarc, Chem. Phys. Lett., 28, 540 (1974).

20. A. L. Buchachenko, Dokl. Akad. Nauk SSSR, 244, 1146 (1979).

21. G. M. Zhidomirov and A. L. Buchachenko, $Z h$. Strukt. Khim., 8, 1110 (1967).

22. A. A. Ovchinnikov, Dokl. Akad. Nauk SSSR, 236, 928 (1977).

23. R. B. Bradburg, N. C. Hanlox, and H. H. Halt, J. Chem. Soc., 1394 (1974).

24. K. Maruyama, S. Morimura, C. Amakasu, T. Toda, and E. Yano, Nippon Kagaku Zasshi, 90, 296 (1969).

25. R. Brire, H. Lemaire, and A. Rassat, Bull. Soc. Chim., Fr., 11, 46, 3273 (1965).

26. M. Balasubramanian and N. Padma, Tetrahedron, 19, 2135 (1963).

27. J. B. Flanagan, S. Margel, A. J. Bard, and F. C. Anson, J. Am. Chem. Soc., 100, 4248 (1978).

28. T. Saji, N. F. Pash, S. E. Webber, and A. J. Bard, J. Phys. Chem., 82, 1101 (1976).

29. T. W. Smith, J. E. Kuder, and D. Wychik, J. Polym. Sci., Polym. Chem. Ed., 14, 2433 (1976). 